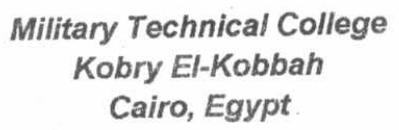

$10^{\text {th }}$ International Conference

On Aerospace Sciences\&

Aviation Technology

\title{
EVALUATION OF DESIGN PARAMETERS OF THE SOLID PROPELLANT STAR GRAIN CONFIGRATION
}

\author{
MAKLED*A., EL-SENBAWI*M. A., ABDALLA*H. M.
}

\begin{abstract}
The star grain configuration has proven to be very attractive for the efficient use of solid propellant rockets. Among the many advantages of star grain are the reduction of the inert mass of rocket motor structure; the protection of the chamber walls from excessive heating; and the possibility to attain relatively wide range of predetermined pressure.

The effects of changes in various design parameters are studied in this paper, each design parameter is treated separately while the other parameters are assumed constant. Different grain shapes are compared, for nearly the same mass of the propellant material. The investigated parameters include grain geometry, initial propellant temperature, erosion of the grain and erosion of the critical diameter.

The results are compiled to demonstrate the variation of the head end pressure with time. The data used for these investigations are picked from real firing of artillery rocket.
\end{abstract}

\section{KEY WORDS}

Solid propulsion, solid rocket, star grain

\section{INTRODUCTION}

During the last decades, very important and significant progress has been achieved in all areas covering the solid propellant rocket motor (SPRM) design and technology. These areas include propellant chemistry and composition, insulation materials, propellant structure, thermal analysis, and performance evaluations.

The star grain configuration is applicable to a relatively wide range of web fractions and propellant mass fraction. It provides reasonably neutral burning characteristics

Egyptian Armed Forces 
in two dimensions without the need of end effects and slots; thus, minimum insulation for protection of the chamber wall is required. In view of these characteristics, the star grain design has been widely used in solid rocket applications.

The star grain configuration has proven to be very attractive for the efficient use of solid propellant rockets. Among the many advantages of star grain one can enumerate:

The reduction of the inert mass of rocket motor structure;

The protection of the chamber walls from excessive heating;

The possibility to attain relatively wide varieties of predetermined pressure histories by the choice of the appropriate geometry.

The seven independent geometric variables (six dimensioniess variables) that define the star make it a very analytic grain configuration with seemingly endless mathematical relationships of practical interest.

Some of these parameters can be changed along the star grain to realize different internal geometric shapes as shown in Fig. 1. The star grain configuration is defined by the following: grain outside radius $R_{C}$, number of star points $n_{p}$, web thickness $\tau_{w}$, fillet radius $f$, cusp radius $r$, star angle $\theta_{f}$, and star point angle $\theta_{p}$. Sometimes instead of $\theta_{f}$ it is preferred to use a dimensionless parameter $\varepsilon=\left(\theta_{f} n_{p}\right) / \pi$, named angular fraction as shown at Fig. $2[1,2,3]$.

It is necessary to mention some important definitions which are essential for optimizing the solid propellant grain. The common specified optimal quantities are the volumetric loading, the sliver fraction and the burning neutrality. Efficient use of propellant implies high volumetric loading and minimum sliver fraction of the solid rocket grain. The burning neutrality is preferred when a nearly constant thrust course is required for less severe accelerations of the missile and better controllability. The often imposed conditions of constant grain diameter or constant grain length represent the optimization constraints $[4,5,6]$.

Frequently, in engineering practice it is not fundamental to have a neutral burning star, but it can be necessary to have a star with a small sliver fraction (for example, the booster of Ariane 3), or a large initial burning surface (as for some micro-rocket igniters), or a star grain with a high volumetric loading fraction (as for space motor) and so on [7].

Generally; for the selection of a star grain configuration, the main factors to be taken into account are:

1. Volume available for the propellant grain;

2. Grain length-to-diameter ratio;

3. Grain diameter-to-web thickness ratio;

4. Thrust versus time curve;

5. Volumetric loading fraction;

6. Manufacture practicality;

7. Fabrication cost.

The optimization for a system incorporating a SPRM consists of a trade off study and consequent designs for each component in order to:

Minimize the gross weight of the rocket for given payload and range, or

Maximize the rocket range for given payload and rocket gross weight.

A mathematical model is used to predict the pressure versus time for a side burning grain The two phases of quasi-steady and tail off transient are treated separately 
Based on this model a computer program is emplemented to cope with grains of different geometries $[8,9]$.

\section{RADIAL EROSION RATE}

Nozzle throat erosion is one of the critical problems encountered in nozzle design. Usually, an increase of throat area larger than $5 \%$ is not acceptable for most rocket applications. Typical values of the radial erosion rate are within the range of 0.01 to $0.25 \mathrm{~mm} / \mathrm{s}$ [1]. The following conclusions can be drawn by analyzing the internal flow equations. The higher erosion rates produce significant lower average chamber pressures, while only a slight change in the average thrust is encountered. As the throat area increases, the expansion ratio is reduced, which will lower the value of the specific impulse.

To protect the nozzle from erosion, and in particular the throat, various technological solutions have been made. As example, a typical nozzle structure with graphite insert is shown in Fig.3. Several models exist for the estimation of the radial erosion rate. For example, the method of Bartz can be used for the estimation of the erosion rate of a motor under design, from previously measured data of a real motor [10].

$$
E_{n}=E_{n, m}\left(\frac{P_{\text {on }}}{P_{\text {on,m }}}\right)^{0.8}\left(\frac{D_{m}^{*}}{D^{*}}\right)^{0.2}
$$

where $E_{n}$ denotes radial erosion rate of the nozzle, $P_{\text {on }}$ chamber pressure, $D$ nozzle throat diameter and $m$ denotes measured values.

In Table 1 are given some measured data which can be used with the Bartz equation.

Table 1 Experimental erosion rates

\begin{tabular}{|l|c|c|c|}
\hline Material & $\begin{array}{c}\text { Average chamber } \\
\text { pressure } P_{0 n, m}(\mathrm{bar})\end{array}$ & $\begin{array}{c}\text { Throat diameter } \\
D_{m}^{*}(\mathrm{~mm})\end{array}$ & $\begin{array}{c}\text { Erosion rate } \\
E_{n, m}(\mathrm{~mm} / \mathrm{sec})\end{array}$ \\
\hline Graphite & 46.4 & 203.0 & 0.129 \\
\hline Graphite & 123.0 & 49.7 & 0.145 \\
\hline Graphite & 80.0 & 64.0 & 0.14 \\
\hline Carbon/Phenolic tape & 50.0 & 331.0 & 0.30 \\
\hline
\end{tabular}

Figure 4 shows the effect of variation of the radial erosion rate on the pressure at the grain. Some motor performance parameters are plotted against the head end of the grain. Som Fig 5 it can be seen that there are a variations of $4.9 \%$ in erosion rate, as shown in Fig.5. It can maximum thrust, $0.47 \%$ in the specific impulse the maximum pressure, $6.7 \%$ in the maxime of erosion rates under consideration.

\section{INITIAL TEMPERATURE OF GRAIN}

The initial propellant temperature affects the rate of burning and hence the performance of the solid propellant motor. The importance of analyzing thermal 
sensitivity of solid propellants can be seen when one recalls that, for example, all weather missiles should operate from $-45^{\circ} \mathrm{C}$ to $+60^{\circ} \mathrm{C}$ or even more.

The effect of the initial temperature of the grain on the burning rate and the maximum expected operating pressure (MEOP) can be expressed by [4]:

where

$$
r=a P^{n}
$$

$$
\begin{gathered}
a=a_{O} \exp \left[\left(\pi_{P}\right)_{k}(1-n) \Delta T_{i}\right] \\
P_{\text {MEOP }}=P_{h, \max }\left[1+n_{1}\left(\frac{\sigma_{P}}{P}\right)\right] \exp \left[\left(\pi_{P}\right)_{k} \Delta T_{i}\right]
\end{gathered}
$$

where $a_{0}$ is a propellant burning rate coefficient, $\left(\pi_{p}\right)_{k}$ is the temerature sensitivity coefficient of pressure, $n$ is the burning rate exponent, $\Delta T_{i}$ is the maximum expected increase in initial grain temperature above design point condition, $P_{h}$ is the pressure at the head end of the grain, $n_{1}$ is the number of standard derivations in maximum chamber pressure, $\left(\frac{\sigma_{P}}{P}\right)$ is statistical variation in the maximum calculated pressure.

Typical values of the temperature sensitivity coeffficent range from $0.67 \times 10^{-3}$ to $2.5 \times 10^{-3} \circ^{\circ} \mathrm{C}^{-1}$ for common propellants [3].

The results of variation of initial grain temperature are shown in Fig.6. Also, some output data are presented in Table 2. The following remarks can be drawn from the
analysis of the shown results.

- The change of pressure is within $20 \%$ while the operating time varies in the range of $23 \%$.

- As the initial grain temperature increases the burning rate and consequently the pressure and thrust are increased while the burning time is reduced.

specific impulse change has very little influence on the total impulse and

The maximum expected operating pressure (MEOP) increases with the temperature increase. This entails a corresponding augmentation of structural

Table.2 Effect of initial grain temperature

\begin{tabular}{|l|c|c|c|}
\hline \multicolumn{1}{|c|}{ Parameter } & $\mathrm{T}_{j}=-20^{\circ} \mathrm{C}$ & $\mathrm{T}_{j}=20^{\circ} \mathrm{C}$ & $\mathrm{T}_{j}=+50^{\circ} \mathrm{C}$ \\
\hline Propellant mass (kg) & 23.95 & 23.89 & 23.88 \\
\hline Maximum head end chamber pressure (bar) & 148.0 & 167.6 & 181.2 \\
\hline Average specific impulse (s) & 243.0 & 244.3 & 215.8 \\
\hline Average total impulse (N.s) & 57036 & 57190 & 57527 \\
\hline Maximum expected operating pressure (bar) & 178.6 & 202.2 & 218.7 \\
\hline Total mass of the empty case (kg) & 11.6 & 13.1 & 14.2 \\
\hline Total mass of the nozzle (kg) & 2.73 & 2.99 & 3.06 \\
\hline Total mass of the loaded case (kg) & 41.5 & 43.3 & 44.4 \\
\hline Operating time (s) & 4.1 & 3.6 & 3.3 \\
\hline
\end{tabular}




\section{NUMBER OF STAR POINTS}

The star shape optimization is generally a trade-off among sliver mass of propellant, neutrality at the first phase and volumetric loading. As the number of star points increases, the port area increases with a corresponding decrease in the burning perimeter and the amount of final sliver[5]. The volumetric loading fractions in the range of 0.7 to 0.9 can be obtained for 3 to 5 star point. The sliver fraction increases significantly with increased volumetric loading[6].

In the present analysis the effect of the number of star grain is investigated, while fixing the other geometrical parameters. The results are plotted in Fig.7. At the beginning of motor operation, as the number of star points increases, a reduction in the pressure is encountered. This can be explained by the increase in the port area associated with the increase in the number of star points. It is to be noted that the most currently used numbers of star point are 6,7 or 8 because they provide fairly thick neutral webs together with important burning areas and sufficiently small port areas[2].

\section{EROSIVE BURNING}

The formula provided by Robillard-Lenoir $[3,10]$, is applied to study the effect of erosive burning:

$$
r=a P^{n}+\alpha_{e b}\left(\frac{\dot{m}}{A_{p}}\right)^{0.8} L^{-0.2} \exp \left(\frac{-\beta r_{p} A_{p}}{\dot{m}}\right)
$$

where $\alpha_{e b}$ is the erosive burning coefficient, $\dot{m}$ is the mass flow rate of gases, $A_{p}$ is the port area, $L$ is the initial grain length, $\beta$ is the erosive burning pressure coefficient, and $\rho_{p}$ is the propellant density.

The results are shown in Fig. 8 . The pressure is shown to be increased at the beginning of motor operation with erosive burning. This can be explained by smaller port area which entails higher gas velocity and subsequent increase in regression rate. However, this effect is reduced as the port area increases with time.

With the non-erosive burning the tail-off period is very short. In such a case the propellant port is nearly cylindrical, while with erosive burning the tapering of the channel occurs along the grain. The tail-off period increases in the case of erosive burning. This is evident because the tail-off starts at the moment when the gases reach the internal chamber wall. This event is affected by the degree of grain tapering.

\section{TAPERING OF THE GRAIN}

The taper shape of the grain is intentially required for two reasons. First, from production point of view, in order to make easy removal of the mandrel from the cast propellant after curing. Second, the effect of erosive burning at the nozzle end can be reduced due to higher port area in this zone resulting from tapering. The developed program $[8,9]$ can handle the presence of two taperings along the grain length as shown in Fig.1. 
In the present investigation, only the effect of tapering due to $Z_{O}$ (see Fig.1) is considered. Figure 9 shows the effect of variation of $Z_{0}$ on the final portion of the pressure- time curve. As the value of $Z_{O}$ increases, much greater regressivity and longer burning time are produced. The longer burning times results from the burning rate reduction which is associated with the reduced pressure.

\section{APEX ANGLE}

The choice of the apex angle in combination of the number of the star points is studied in absence of erosion[2]. According to this study, this angle can be selected such that burning neutrality can be achieved. For example a 7 - point star having half-apex angle of $35^{\circ} 55^{\prime}$ will burn neutrally in the first phase. If higher angle is chosen the burning tends to be progressive; the opposite is true for smaller angle.

The present study deals with erosion, which should be accounted for in real design This is treated in the present study. Figure 10 shows the effect of variation of the apex angle on the pressure-time history. It can be seen that this effect is clear only at the beginning of the motor operation. For the mentioned example $\left(n_{p}=7, \theta_{p} / 2=\right.$ $\left.35^{\circ} 55^{\prime}\right)$, the real burning is shown to be regressive rather than neutral. This can be explained by erosive burning effect. However, with higher apex angle the regressively is decreased.

\section{SHAPE OF THE GRAIN SECTION}

The effect of changing the configuration of the grain cross-section on the pressuretime curve is analyzed as compared to the basic star configuration; (Fig.3). The motor dimensions and the propellant weight are kept unchanged.

Two additional cases are studied for copmparisison:

Case 1: A grain with tubular cross-section, Fig.11(a). The internal diameter is adjusted to provide the same weight of the propellant.

Case 2: A truncated grain (also called slotted tube), Fig.11(b).

The results of the three studied configurations are shown in Fig.12 in order to provide a clearer demonstration of the shape effect. In conclusion, the tailoring of the pressure- time curve can be done through the clever selection of the grain geometric parameters.

The larger burning burning surface demonstrated in case 2 at the start of burning leads to a higher initial pressure in comparison with the other cases. Unfortunately, a larger tail-off period is encountered, which can be explained by the important portion of sliver as indicated by the burning perimeter contours.

\section{CONCULUSION}

A comprehensive analysis of the geometry of the star grain, which has a wide range of application in the SPRM's is presented. The choice of optimum configuration for the minimum sliver fraction, maximum volumetric loading and required level of neutrality is discussed on the basis of the presented geometric formulations. The optimization can be carried out for the given constraints (for example the grain 
diameter) by the appropriate selection among the many configurations composed by different combinations of the variables defining the star. The objective parameters are calculated for each configuration and used as the selection criteria.

The present investigation covers the effect of changes in various design parameters. It is shown that the increase in the nozzle throat erosion rate tends to reduce the maximum chamber pressure. While an increase in the initial temperature of the grain leads to a remarkable increase in the maximum chamber pressure, it has a little influence on the total and specific impulses.

\section{REFERANCES}

1- George, P. Sutton, 'Rocket Propulsion Elements'. Sixth Edition, John Wiley \& Sons, New York, 1992.

2- Barrère M. et al., 'Rocket Propulsion', Elsevier Publishing Company, 1960.

3- Alain Davenas, 'Solid Rocket Propulsion Technology', Pergamon Press, Oxford, 1993.

4- Richard H. Sforzini, 'Design and Performance Analysis of Solid Propellant Rocket Motors', NASA Contractor Report, (NASA CR-129025), October 1972.

5- Krishnan S., 'Design of Neutral Burning Star Grains', Jet Propulsion, Vol.12, No.1, January 1975.

6- Brooks Wm. Ted, 'Ballistic Optimization of the Star Grain Configuration', Jet Propulsion, Vol.19, No.1, Jan-Feb, 1982.

7- Andrea Ricciardi, 'Generalized Geometrric Analysis of Right Circular Cylindrical Star Perforated and Tapered Grains', Jet Propulsion, Vol. 8, No.1, Feb., 1992.

8- Ah. Makled "Design Optimization of Solid Rocket Motors" M.Sc. thesis, department of Rockets, MTC, Cairo, 1994.

9- Ah. Makled, H. M. abdalla and M. A. el-senbawi "Prediction of the Pressure and Thrust Histories For a Solid Burning Grain" $7^{\text {th }}$ Conference Applied Mechanics And Mechanical Engineering, 28 - 30 May, MTC, Cairo, Egypt.

10- Lenoir J. M. and Robillard G., 'A Mathematical Method to Predict the Effects of Erosive Burning in Solid Propellant Rocket', Sixth Symposium (International) on Combustion, Reihold, New York, pp.663-667, 1957. 


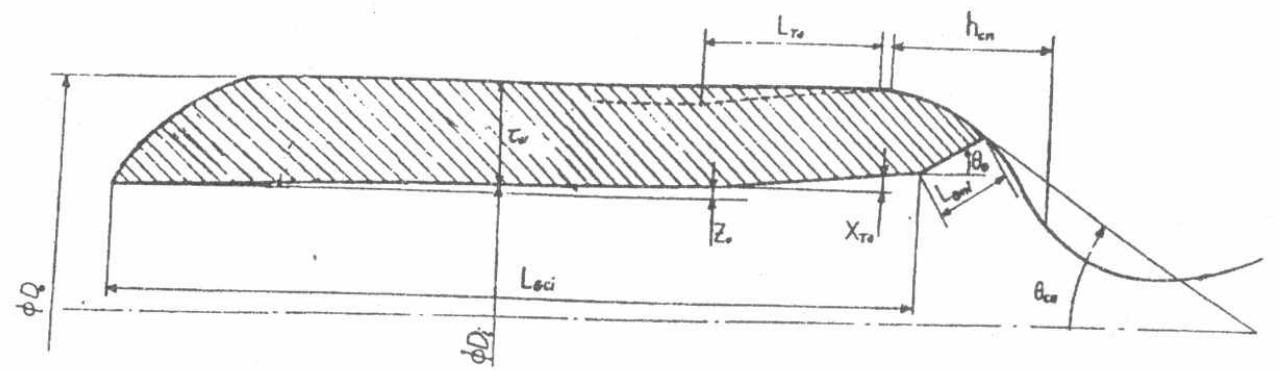

Fig.1 Basic dimension of solid propellant grain

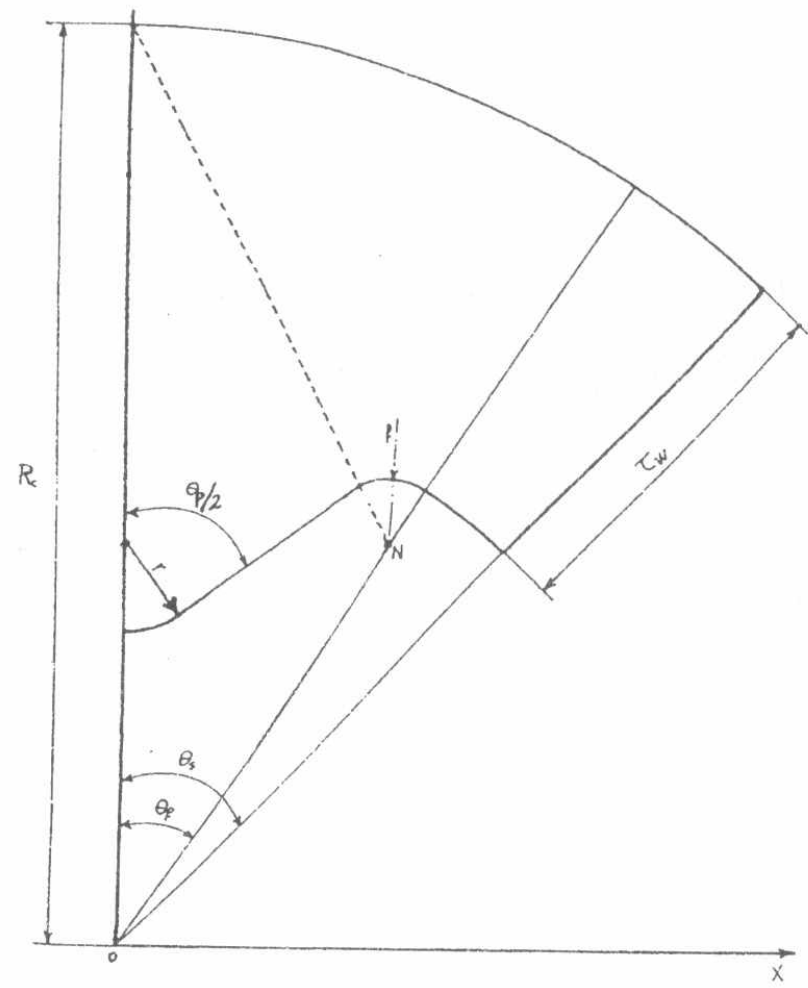

Fig.2 Convex point star grain configuration

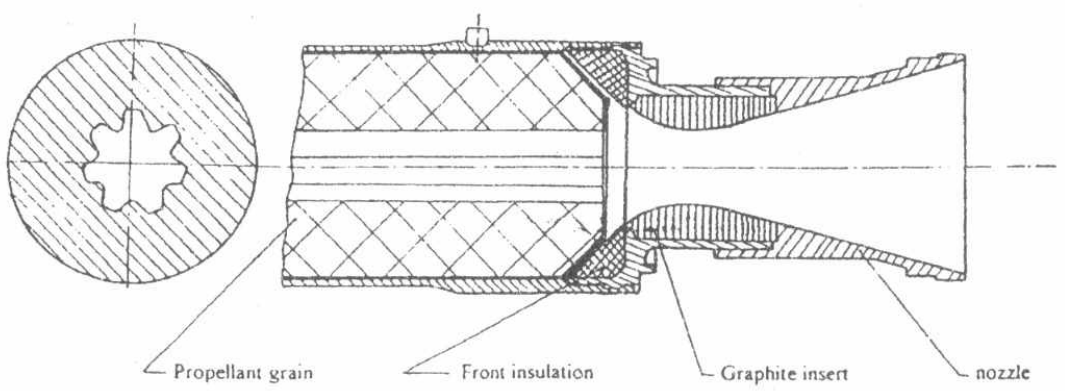

Fig 3 Typical motor with star grain and nozzle graphite insert 


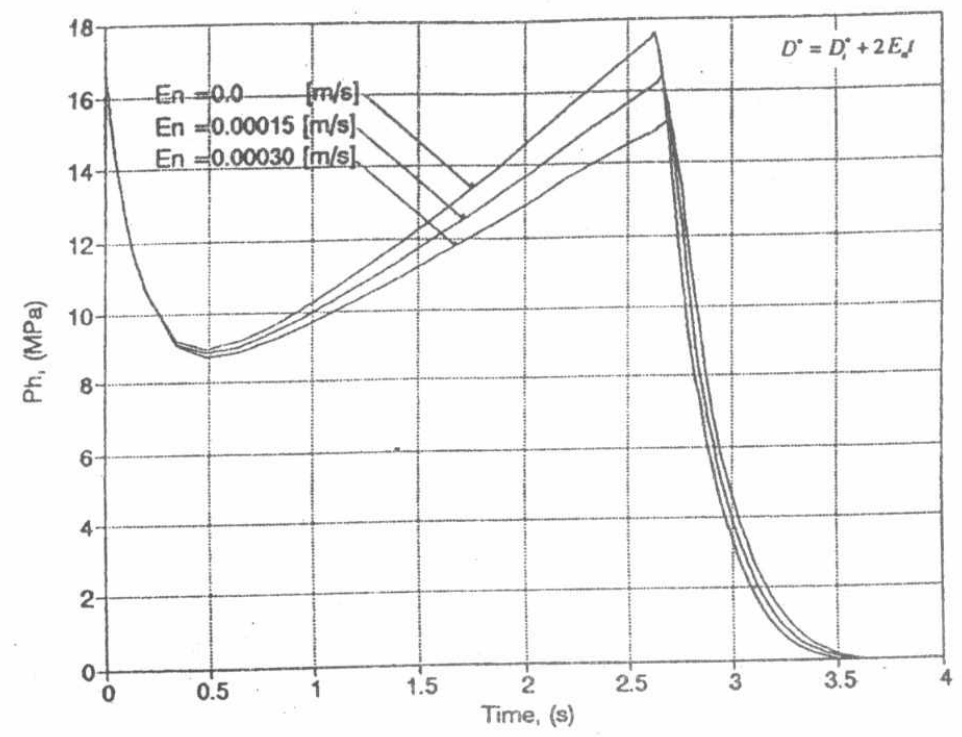

Fig. 4 Head end pressure versus time for various nozzie radial erosion rates

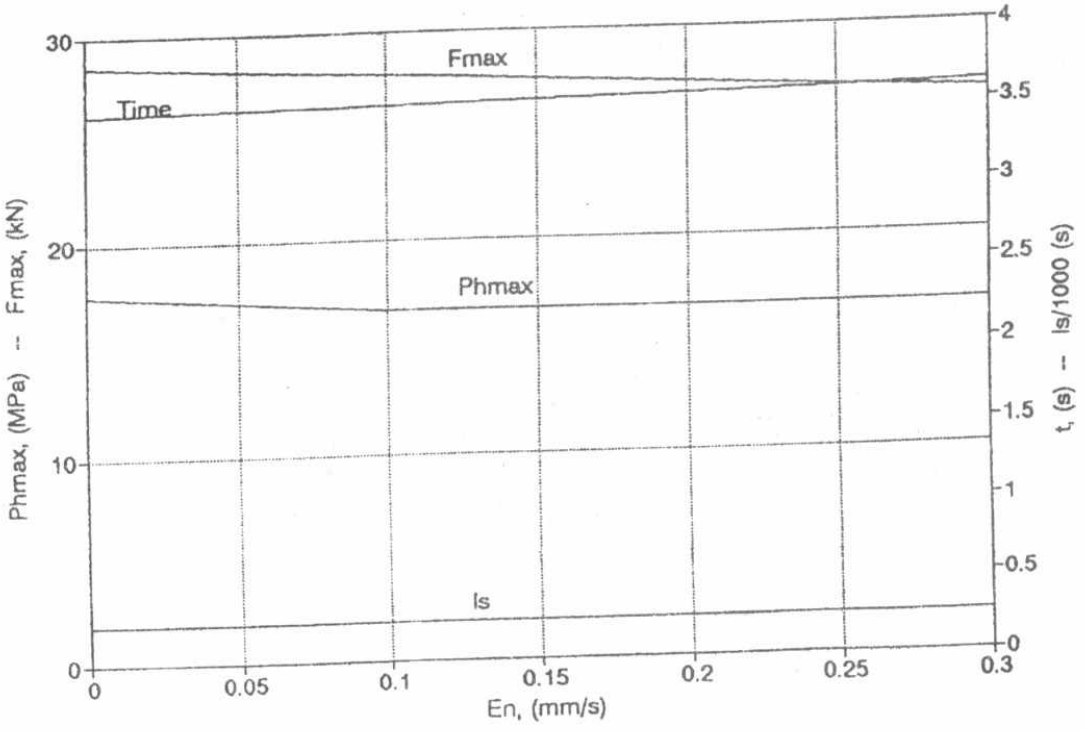

Fig. 5 Variation of motor performance parameters with the erosion rate 


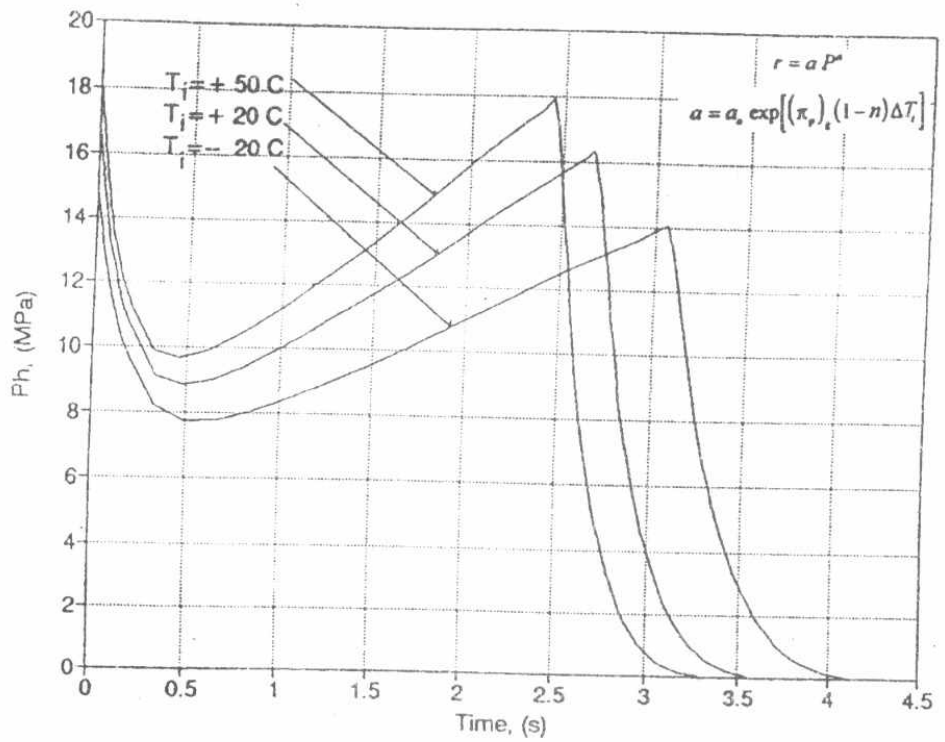

Fig. 6 Head end pressure versus time for various initial grain temperatures

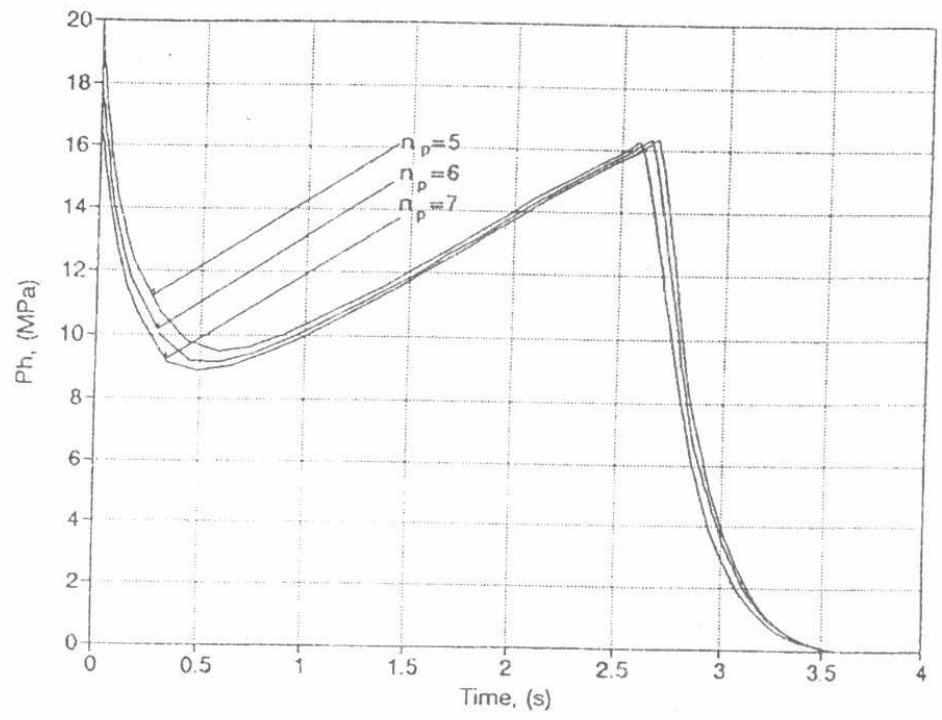

Fig. 7 Head end pressure versus time for various number of star points 


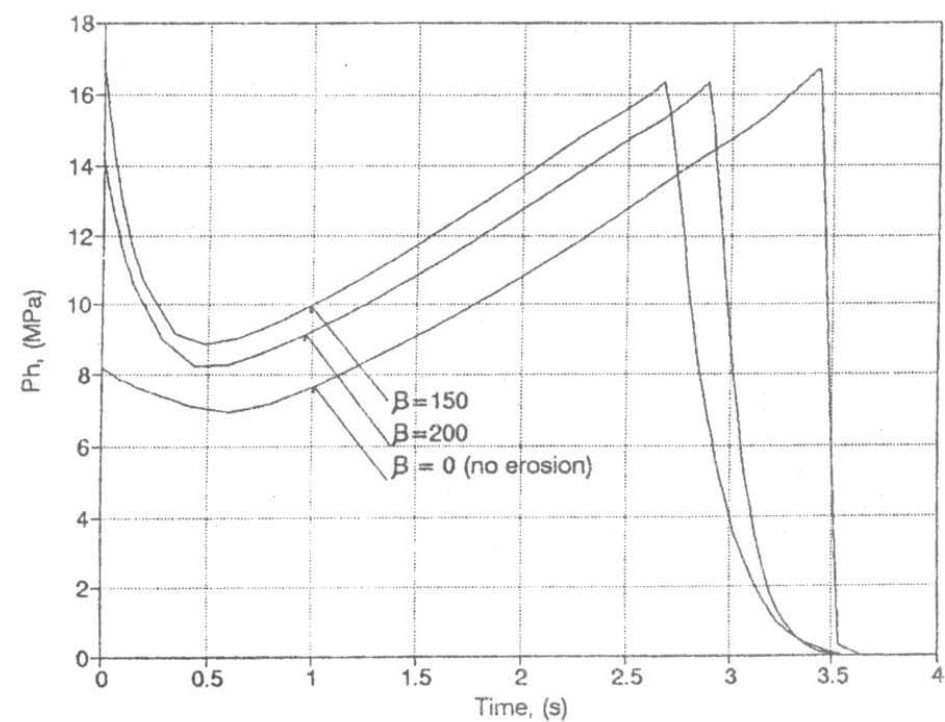

Fig. 8 Head end pressure versus time for different erosion burning constant $\beta$, (Eq.5)

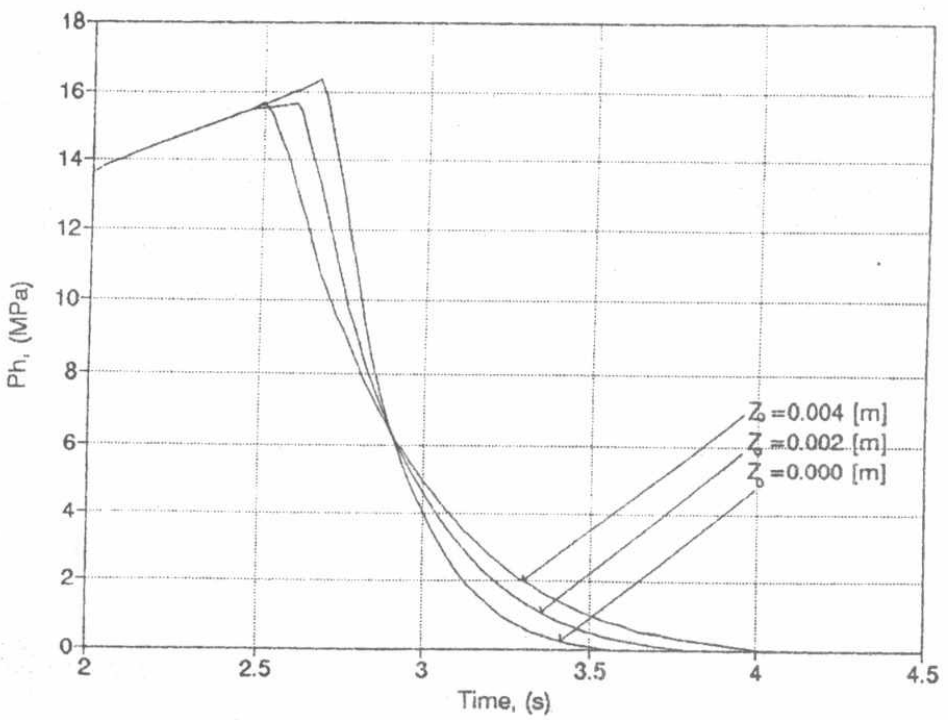

Fig. 9 Head end pressure versus time at the final portion for various values of $Z_{0}$ 


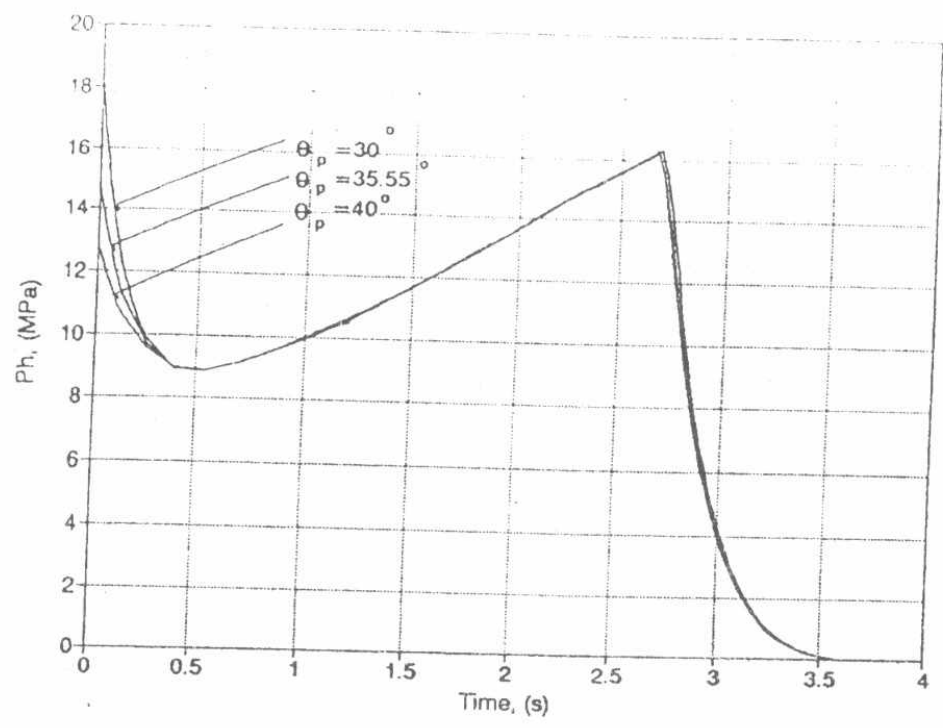

Fig. 10 Head end pressure versus time for various star point angles
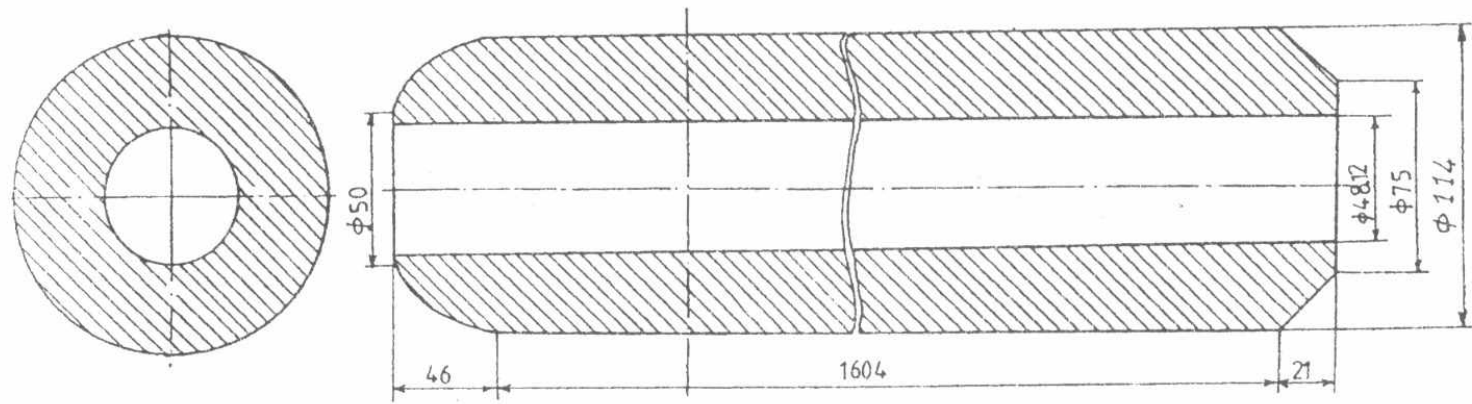

(a) Tubular grain
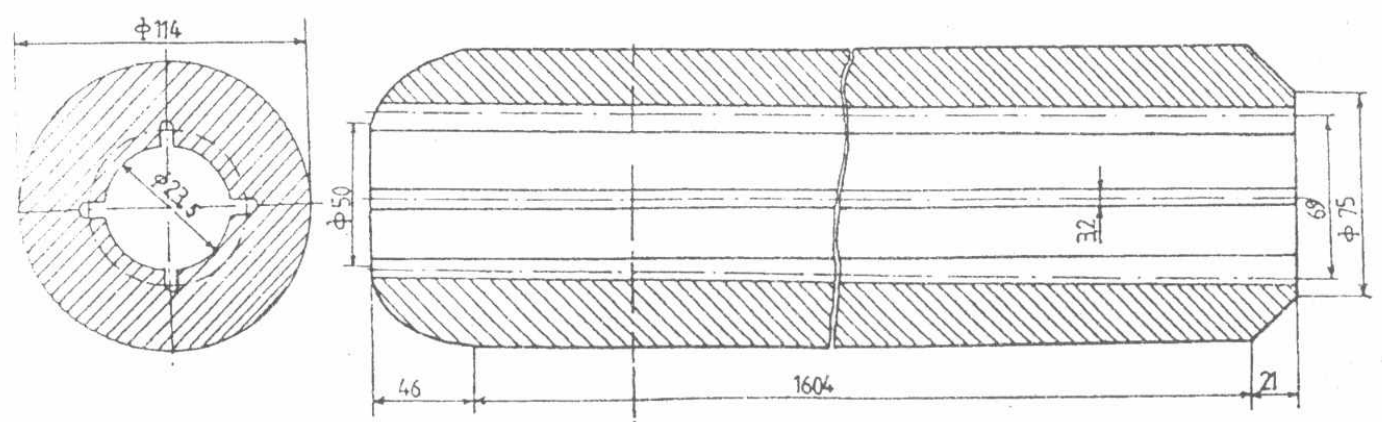

(b) Truncated (slotted) grain

Fig. 11 Tested cross-section configuration 

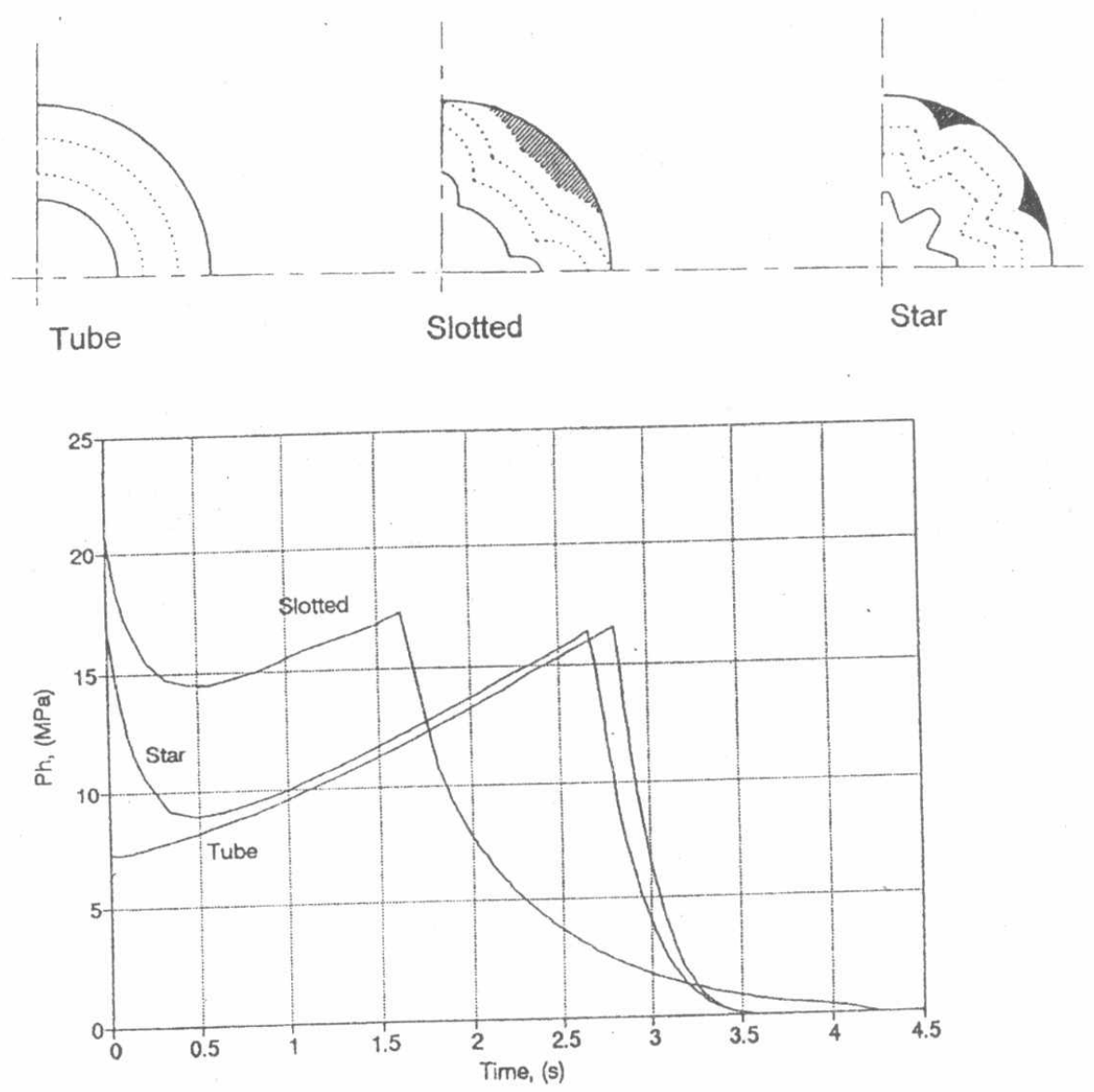

Fig. 12 Head end pressure versus time for different shapes of grain 